\title{
A Review of the Basic Teaching Thoughts of Legal School in Sculpture Teaching in Chinese Academy
}

\author{
Bo Qin ${ }^{1, *}$ \\ ${ }^{1}$ Jingdezhen Ceramic Institute, Jingdezhen, Jiangxi 333403, China \\ *Corresponding author. Email: $381091841 @ q q . c o m$

\begin{abstract}
In the last century, sculptors returning from studying France combined the French academic sculpture teaching mode with their respective artistic ideas, and gradually formed the French teaching tradition in the sculpture teaching of the Chinese Academy in teaching practice. French sculpture teaching emphasizes basic skills training, with relatively short course time and casual arrangement, and it attaches importance to the cultivation of students' awareness. The content of the course is mainly human body sketching, and the boundary between basic training and creation is relatively blurred.
\end{abstract}

Keywords: sculpture, teaching, college of fine arts

\section{INTRODUCTION}

In recent years, with the reform and development of China's higher education, the enrollment scale of the college of fine arts has expanded rapidly, and the professional foundation level of students has generally declined when they entered the school. Undergraduate education is the main body and foundation of higher education. Grasping the teaching of undergraduate is the focus and key to improving the quality of education. The undergraduate teaching focuses on the foundation. High buildings rise from the ground. The foundation determines the height of a student's art development. Confucius said: "Getting new knowledge by reviewing the old knowledge, you will be a teacher." The pioneers of modern Chinese sculpture education in the last century had a lot of insights in basic teaching. It is the responsibility and obligation of the latecomers to take stock of their teaching ideas so that they can play a greater role in the current teaching reform.

\section{LEARNING FROM THE WEST}

Throughout China's long history, sculpture has not achieved such a prominent position as calligraphy and painting. For example, the famous "Twenty Pins of Longmen", as the model of the stela of Wei Dynasty, was sought after by writers of all ages. Originally, it was only an inscription on the statue of the cave. The main body of the cave, the exquisite sculpture of the Buddha, has been ignored for a long time. This is because the sculpture creation has a strong color of manual labor, which cannot attract the scholarbureaucrats to participate. After the defeat of several foreign wars in the late Qing Dynasty, the social elites realized that simply learning Western technology could not achieve the goal of a prosperous country with a powerful army, and began to try to fully understand and learn from the West in politics, economy and culture. People marveled at the neatness and gorgeousness of European city construction, and were also attracted by the sculptures all over the streets. Sculptures had become one of the symbols of Western culture like oil paintings and western houses. The concept of sculptures known as art had been gradually accepted by the Chinese cultural class. Furthermore, some people of insight realized that sculptures have an important role in honoring heroes and cultural celebrities and enhancing national cohesion in addition to beautifying the city. The Chinese youth who went to Europe to study sculpture were holding these ideals to ship to foreign countries to study. Most Chinese students chose to enter the École Nationale Supérieure des Beaux-arts de Paris to study sculpture. Although the classical sculptures of the École Nationale Supérieure des Beaux-arts de Paris had been declining at this time, in the views of the Chinese, Paris of France was still the center of Europe, and the École Nationale Supérieure des Beaux-arts de Paris represented the orthodoxy of the European art, which is why the foreign students who studied sculpture in Belgium, Japan and the United States at the time did not as influential as the students studied in France. After returning to China, the foreign students established the sculpture major in the art technical colleges. They combined the French academy sculpture teaching mode with their own artistic ideas and promotions, and gradually formed the French teaching tradition of the sculpture teaching in the Chinese academies. In the 1950s and 1960s, after the spread of the Soviet realism sculpture teaching mode in major art colleges, the French sculpture teaching gradually declined. The impact was limited to the Central Academy of Fine Arts and China Academy of Fine Arts 
(Zhejiang Academy of Fine Arts). This article selects Wang Linyi, Hua Tianyou, Liu Kaiqu, and Cheng Manshu, four traditional representative figures of the French school of sculpture teaching to explore the basic teaching ideas of French school.

\section{WANG LINYI AND HUA TIANYOU}

Wang Linyi (1908-1997), studied sculpture at the Paris Fine Arts School from 1931 to 1935 , and returned to China in 1935 to serve as a professor at Peiping Art Technical College. After liberation, he served as the director of the Sculpture Department of the Central Academy of Fine Arts. Wang Linyi hadn't written an article about his teaching thoughts during his life. According to the articles from the students' memories of his life and the author's interview with Liu Shiming, his teaching can be summarized as the following characteristics:

- In terms of the content and arrangement of the course, clay sculpture was taken as the main body. Student's first sculpture assignment is a work of female body (24 lessons);

- The homework time was coordinated by the students themselves, and the class hours were basically 1 week to 2 weeks. Sometimes it will be decided whether the homework should be continue based on the progress of the homework;

- There is no specific rule of scale for the homework, which was controlled by the students themselves, generally 80 to $100 \mathrm{~cm}$;

- The sketches were arranged by the school uniformly.

Wang Linyi's teaching method advocated teaching students according to their aptitude, and inspiring and enlightening according to the characteristics of students. He never affirmed or denied students' works in classes, so that students can explore their own artistic path with confidence. His students Liu Xiaocen, Liu Shiming, and $\mathrm{Yu}$ Jinyuan, "have their own characteristics in the same class that one is known for 'line', one is for 'face', and one is for 'body'. They all made good grades. And this characteristic runs through their lives." 1 Wang Linyi's teaching method is undoubtedly suitable for art education, and the success rate is quite high.

Qian Shaowu: Review of the 38-year history of the Department of Sculpture. Yin Shuangxi, Sui Jianguo, chiefly-edited, Traveling through Time and Space - Selected Papers of Teachers from the Sculpture Department of the 80th Anniversary of the Central Academy of Fine Arts, Xi'an: Shaanxi People's Fine Arts Publishing House, Feb. 1998, p95.
You Tianyou (1901-1986) studied at the École Nationale Supérieure des Beaux-arts de Paris from 1934 to 1948 and returned to China in 1948. He successively served as a professor at the Peiping Art Technical College and the Sculpture Department of the Central Academy of Fine Arts. You Tianyou combined the "six methods" in traditional Chinese painting theory with sculpture creation and teaching, and used this as a basis to construct a set of teaching plans for implementation. He believed that the purpose of basic teaching is to master the human body modeling knowledge necessary for creation. The knowledge includes: the laws of movement, the laws of organization, and artistic skills. He believed that the training of the sculpture department first requires students to recognize and master the laws of movement and organization, and on top of that, their artistic skills also need to be trained. "It is necessary to understand what sculpture language is, to be able to break through the norms and create", and finally "to achieve the level of both implicit and unrestrained that it can be beautiful if you want it to be, and humble if you want to be humble"2. In teaching organization, he was adhering to follow the laws of cognition, "from emotional cognition to rational cognition, from rational cognition to application", so that students can gradually obtain the skills "from basic knowledge to mastering the law, applying the law, and improving to artistry"3. In order to train step by step, Hua Tianyou planned the learning steps of each grade, and clearly specified the teaching purpose and requirements of each stage. At each stage, one or more of the six methods will be adapted, being convenient for students to understand and master. Although the course focused on exercises of head and body sketching of human, Hua Tianyou did not advocate a single content of teaching. He believed that "sketches should be combined with facsimileing, observation, rapid modeling, long-term sketching, and blind modeling as the whole process", and explained the purpose and teaching arrangement of these training forms: "rapid modeling can be used as confirming the positive new feeling before sketching in each large unit, and blind modeling can be used after the large unit, as a confirm of the harvest. Facsimileing can be arranged between the two stages of summing up previous experience and further improvement, for inspiring the

2 Hua Tianyou: My Views on the Basic Training of Sculpture. Yin Shuangxi, Sui Jianguo, chiefly-edited, Traveling through Time and Space - Selected Papers of Teachers from the Sculpture Department of the 80th Anniversary of the Central Academy of Fine Arts, Xi'an: Shaanxi People's Fine Arts Publishing House, Feb. 1998, p1.

Traveling through Time and Space - Selected Papers of Teachers from the Sculpture Department of the 80th Anniversary of the Central Academy of Fine Arts, p2. 
new stage." ${ }^{4}$ He emphasized the reference and research of previous works, and advocated that "in the process of research, we should gradually study the ancient and modern Chinese and foreign masterpieces at the same time, to learn from the experience of previous people and the rules they found to confirm whether they have obtained the right or have more gains". At each stage of the study, he prescribed corresponding masterpiece appreciation. In the arrangement of teaching content, he advocated that the training can be divided into staged training and unit training.

- Staged training: "the handy training that the lower grades (grades 1 to 2 and 3) learn the basis, the senior grades are gradually improved to the artistry based on the original foundation, and finally the students can mix what they've learnt into a flexible application." 5

- Unit training: "Small and large units work together. The first unit has a short time and is designed for general learning. The second unit is longer, so it can be faster. The time required for the first unit is condensed within this unit, so that the longer time can be used for more experience. The third unit can be longer, and further accumulate experience, and then it can be gradually accelerated and lengthened in order to improve, rather than treat equally. "6

Hua Tianyou's teaching assumptions formed a complete and unified system in the teaching purpose, content and organization. The introduction of the "six methods" into sculpture teaching was based on an indepth study of Western sculpture traditions and teaching and a deep understanding of traditional Chinese art, and had gradually matured through testing in its own creative and teaching practice. Hua Tianyou guided a way for future generations on the road of establishing a sculpture teaching system suitable for his own nation. For various reasons, his teaching ideas had not been fully implemented, and his teaching ideas had not received enough attention.

\section{LiU KAIQU AND Cheng MANShU}

Liu Kaiqu (1904-1993), studied at the École Nationale Supérieure des Beaux-arts de Paris in 1928, returned to China in 1933 as the director of the Sculpture Department of the National Technical

Traveling through Time and Space - Selected Papers of Teachers from the Sculpture Department of the 80th Anniversary of the Central Academy of Fine Arts, p4

Traveling through Time and Space - Selected Papers of Teachers from the Sculpture Department of the 80th Anniversary of the Central Academy of Fine Arts, p4.

Traveling through Time and Space - Selected Papers of Teachers from the Sculpture Department of the 80th Anniversary of the Central Academy of Fine Arts, p4
College of Fine Arts, and served as the dean of the East China Branch of the Central Academy of Fine Arts (now China Academy of Fine Arts) in 1949. In 1959, he served as the Deputy Dean of the Central Academy of Fine Arts, and presided over the teaching of the second session of the sculpture advanced research class. Liu Kaiqu emphasized truth-seeking in his basic teachings, and believed that exaggeration is for sculpture creation. For the purpose of basic teaching, he had a clear statement: "First, it is to understand the structure of the human body, movement changes and the laws of personality. Second, it is to exercise observation ability, generalization ability, organization ability, modeling ability and the ability of skillful using sculpture materials. Third, it is to learn the production steps and solving the difficulties and problems that may encounter in processing. Forth, through the above practices, it is to achieve the ability to truly and vividly reflect the object." ${ }^{7}$ Liu Kaiqu believed that the realistic sculpture foundation is more conducive to the formation of the artist's personal style and expression. He didn't advocate that students should copy the methods and forms of a master or an ancient person on the surface. Liu Kaiqu presided over the teaching work of the graduate class of the Central Academy of Fine Arts twice in 1960 and 1978. His teaching ideas had a great influence on the sculpture industry in China.

Cheng Manshu (1901-1961) studied sculpture in the Cole Nationale des Beaux-arts de Lyon and the École Nationale Supérieure des Beaux-arts de Paris from 1925 to 1936. In 1944 he was appointed as a professor of National Technical College of Fine Arts. Cheng Manshu believed that "the purpose of basic courses is to master and express the specific characteristics and personalities of the objects, and at the same time understand the common characteristics of humansanatomical structure." He believed that "the emphasis should be on the correctness of the body and the vividness of the image. If the students can correctly shape the complete work, they have already completed the required assignments." "The purpose of the basic lesson is to express objects, not to create new ways." 8 The strict requirements in teaching would sometimes completely deny the students' homework. He did demonstration work for students and often revised students' assignments in person. Regarding the relationship between work and creation, he used to believe that "good work is creation" in pursuit of the formal beauty of the human body in the early period, but he was changed by the influence of revolutionary literary theory.

Liu Kaiqu, Liu Kaiqu's Sculpture Digest: On the Basic Practice of Clay Sculpture, Lin Wenxia, assisted in organizing, New Arts, 1983, 2, p47.

Shen Haiju, Cheng Manshu's Sculpture Teaching, New Arts, 1984, 02, p24. 


\section{Conclusion}

Although the four professors had differences in teaching ideas and teaching methods, the basic teaching ideas of the French sculpture teaching tradition can still be summarized from them:

- Emphasis on basic skills training, which is the same as the Soviet sculpture teaching mode;

- The arrangement of lesson time is more casual. The length of the lesson is determined according to the student's progress, without being as rigid as the Soviet teaching mode;

- The course time is relatively short. It emphasizes feeling and personal observation and comprehension, pays attention to finding subtle fluctuations between object shape and volume, and cultivates students' perception ability;

- The content of the course is mainly human body sketching, and the boundary between basic training and creation is blurred.

\section{References}

[1] Liu Kaiqu, Liu Kaiqu's Sculpture Digest: On the Basic Practice of Clay Sculpture [J]. Lin Wenxia, assisted in organizing, New Arts, 1983, 2. (in Chinese) Pan Yaochang, ed. History of Chinese Modern Art Education [M]. Hangzhou: China Acadamy of Art Press, May. 2002. (in Chinese)

[2] Pan Yaochang, ed. Chinese Art Education in the 20th Century [M]. Shanghai Painting and Calligraphy Publishing House, Sept. 1999. (in Chinese) Yin Shuangxi, Sui Jianguo, Traveling through Time and Space - Selected Papers of Teachers from the Sculpture Department of the 80th Anniversary of the Central Academy of Fine Arts [M]. Xi'an: Shaanxi People's Fine Arts Publishing House, Feb. 1998. (in Chinese)

[3] Sun Zhenhua, Looking back on the century situation - On the sculpture teaching of China Academy of Art [A]. Towards the Wasteland: Sun Zhenhua's Sculpture Collection [C]. Nanning: Guangxi Fine Arts Publishing House, Feb. 1999. (in Chinese)

[4] Shen Haiju, Cheng Manshu's Sculpture Teaching [J]. New Arts, 1984, 02. (in Chinese)

[5] Wang Ziyun, From Chang'an to Athens: Chinese and Foreign Art Archeology Travels [M]. Changsha: Yuelu Press, Aug. 2005. (in Chinese)

[6] Xing Li, Consciousness and Norms - European Academy of Fine Arts, 16th to 19th Century [M]. Beijing: China Renmin University Press, Sept. 2004. (in Chinese)

[7] Zhang Wei, Zhou Simin, Chen Ke, Four Seasons Like Songs Sculpture Department of Repin Academy of Fine Arts, Russia [M]. Beijing: People's Fine Arts Publishing House, June. 2004. (in Chinese) 